\title{
Chylothorax: A Rare Complication of Endoscopic Thoracic Sympathectomy
}

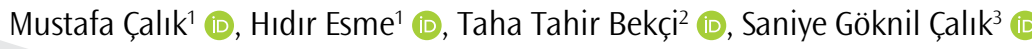

Hyperhidrosis $(\mathrm{HH})$ is a pathological condition of excessive secretion of the eccrine sweat glands in amounts greater than that required for physiological needs. Herein, we describe a patient who was treated with autologous blood pleurodesis for ductus thoracicus injury after endoscopic thoracic sympathectomy. A 23-year-old woman was admitted to our clinic with a complaint of bilateral pronounced axillary $\mathrm{HH}$, minimal sweating of the hands, and bruising. She underwent bilateral thoracic sympathectomy at levels T3 and T4. A milky fluid was observed in the left chest tube and was diagnosed as chylothorax. No similar case of postoperative chylothorax treated with autologous blood pleurodesis has been found in the English literature. According to anatomical variations, the ductus thoracicus is susceptible to injury even in the hands of an experienced surgeon. In case an injury has occurred shortly after thoracic sympathectomy, autologous blood pleurodesis is an effective treatment for chylothorax. This procedure is safe and cheap and can be easily performed at the bedside.

Keywords: Chylothorax, thoracic, sympathectomy, pleurodesis, autologous blood

This study was presented in the American College of Chest Physicians CHEST Congress 26-31 October 2013, Chicago, USA.

ORCID IDs of all authors: S0000-0001-9963-5724; H.E. 0000-0002-6569-8193; T.T.B. 0000-00025705-8452; S.G.C.. 0000-0002-6569-8193.

${ }^{1}$ Department of Thoracic Surgery, Health Sciences University Konya Training and Research Hospital, Konya, Turkey.

${ }^{2}$ Department of Pulmonary Medicine, Health Sciences University Konya Training and Research Hospital, Konya, Turkey.

${ }^{3}$ Emergency and First Aid Program, Vocational School of Health Services KTO Karatay University, Konya, Turkey.

\section{Address for Correspondence: \\ Mustafa Çalık}

E-mail: drmcalik@hotmail.com

Received: 16.04.2017

Accepted: 28.10.2017

(C) Copyright 2018 by Available online at istanbulmedicaljournal.org

\section{Introduction}

Hyperhidrosis $(\mathrm{HH})$ is a pathological condition of excessive secretion of the eccrine sweat glands in amounts greater than that required for physiological needs. HH occurs more commonly in women and is usually bilateral and symmetrical. It often begins in early childhood and usually persists throughout adulthood, resulting in severe occupational, emotional, and social disabilities (1). Although the prevalence of $\mathrm{HH}$ is thought to be low, it has been reported as $2.8 \%$ in the United States and $4.9 \%$ in China (2). Various treatment methods have been recommended for HH. Generally, the preferred treatment method varies according to the clinician. The success and compliance rates of medical treatments are significantly lower, particularly in patients with life-long or moderate to severe $\mathrm{HH}$. Permanent management can be achieved through invasive techniques such as sympathectomy. Except for one series, no mortality has been reported, with a morbidity not exceeding 5\%, in the English literature. Pneumothorax is the most common complication (2\% of patients; a total of $25 \%-30 \%$ exclusively require thoracic drainage), followed by subcutaneous emphysema (1\%) and pleural effusion (0.3\%-0.5\%), which rarely requires drainage. Solitary cases of complications, such as chylothorax, hemopericardium, lesions of the superior intercostal vein, pulmonary edema, or brachial plexus lesions, have been reported in a previous study (1). Herein, we describe a patient who was treated with autologous blood pleurodesis for ductus thoracicus injury after endoscopic thoracic sympathectomy.

\section{Case Report}

A 23-year-old woman was admitted to our clinic with a complaint of bilateral pronounced axillary $\mathrm{HH}$, minimal sweating of the hands, and bruising. She underwent bilateral thoracic sympathectomy at levels T3 and T4 via a diathermy hook inserted through the thoracoscope (Karl Storz Hopkins $0^{\circ} 26034$ AA Laparoscope Tuttlingen,Germany). Electrocautery ablation of the accessory nerve and Kuntz branches was composed of approximately $3 \mathrm{~cm}$ to prevent recurrence at the level of the third rib. Chest X-ray was obtained in the recovery room after surgery to verify full expansion of the lung (Figure 1). Then, the patient was transferred to the intensive care unit (ICU). Oral nutrition was initiated $6 \mathrm{~h}$ after surgery. Four hours after initiating enteral feeding, a leakage of $100 \mathrm{~mL}$ milky fluid was observed in the left chest tube. In the biochemical assessment of the pleural drainage fluid, $12 \mathrm{mg} / \mathrm{dL}$ of cholesterol and $310 \mathrm{mg} / \mathrm{dL}$ of triglyceride were noted. The patient was diagnosed with postoperative chylothorax. Enteral feeding was terminated. She was treated with total parenteral nutrition via a central venous catheter. The right pleural drain was removed after the first postoperative day. Daily pleural drainage was $60 \mathrm{~mL}$ on the second day and $40 \mathrm{~mL}$ on the third day. A follow-up of blood chemistry and electrolyte 


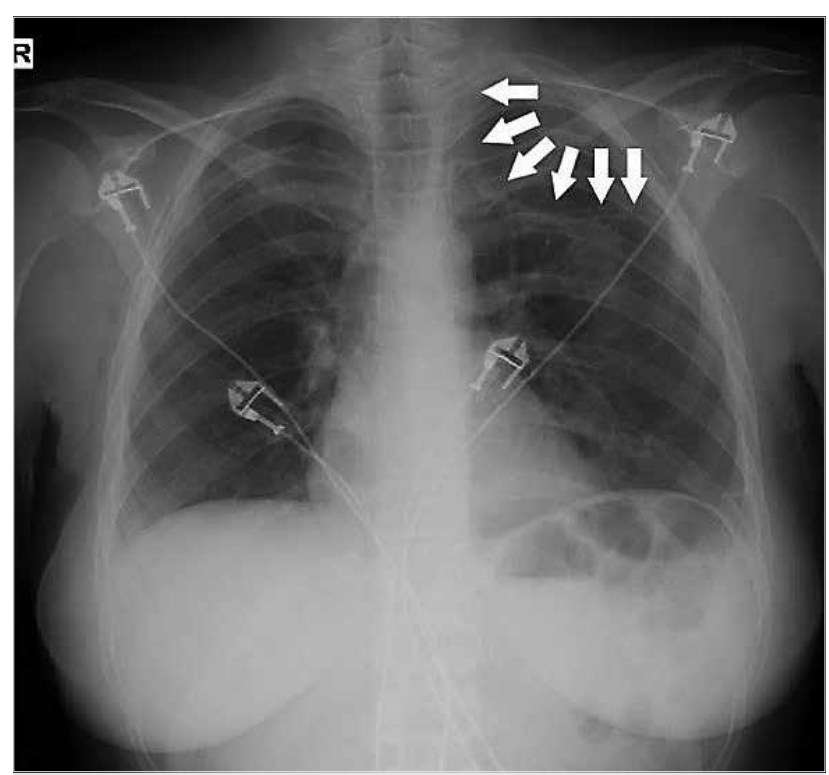

Figure 1. The patient's chest X-ray was obtained in the recovery room after surgery to verify the full expansion of the lung (Chest tube was indicated by white arrows)

levels was also conducted. Pleurodesis was achieved via a chest tube on the fourth day of hospitalization when drainage ceased. Then, $50 \mathrm{~mL}$ of autologous blood was obtained on the fourth day of admission. Immediately, blood extracted from the patient was injected into the pleural space through the chest tube. Then, it was removed on the same day. The patient was discharged on the seventh day of admission without complications. At 24 months of follow-up, she had no further recurrence of effusion. Written informed consent was obtained from the patient to participate in the present study.

\section{Discussion}

Although benign in nature, $\mathrm{HH}$ might cause significant social, emotional, and professional disabilities in patients who generally cannot be adequately treated with conservative methods (3). Conservative methods are generally used only for patients with mild symptoms. Thus, the majority of patients with mild to severe $\mathrm{HH}$ will sooner or later be recommended for surgery as precise treatment. There is no doubt that thoracoscopic sympathetic surgery has provided a highly reliable solution for $\mathrm{HH}$. This has been shown in a clinical report of successful control of symptoms by surgery in more than $95 \%$ of patients (2). The overall rate of complications is less than $5 \%$, and these are minor complications. Chylothorax is an extremely uncommon complication due to thoracoscopic sympathectomy but continues to be a formidable clinical problem of any thoracic surgical practice. In the English literature, eight cases of chylothorax after sympathectomy have been reported, one via transaxillary sympathectomy and seven via thoracoscopy.

Chylothorax is the accumulation of lymphatic fluid in the pleural cavity due to ductus thoracicus and damage to the lymphatic vessels. Postoperative chylothorax that develops after thoracic sympathectomy is a rare case and generally can be observed in 0.5\%-2.5\% of patients after cardiac and thoracic surgeries. Traditional conser- especially in high-output fistulae (4). Chylothorax was observed in our patient. The route of the thoracic duct varies in $40 \%-60 \%$ of individuals. Anatomical variations make it more susceptible to accidental injury during thoracic surgery. Its route is anomalous and unpredictable (5).

Typically, postoperative chylothorax occurs 2 to 10 days after surgery. However, in our case, it occurred in a much shorter time, i.e., only $4 \mathrm{~h}$. The most common symptoms in patients with chylothorax are shortness of breath and cough. None of these symptoms were exhibited in our patient. However, she had chest pain, which is rarely observed in patients with chylothorax.

Current treatments of chylothorax include conservative, surgical, and radiation therapies. The management of postsurgical chylothorax is guided by a set of principles rather than a strict algorithm. These principles include efficient drainage of the effusion, cessation of flow through the thoracic duct, and obliteration of the pleural space (6). Pleural obliteration is also used to prevent prolonged air leakage and fluid accumulation in the pleural space. A wide variety of sclerosing agents are used for this procedure. Among these, autologous blood, which is less toxic and injurious to the lung tissue than traditional chemical substances, has been used since 1987 in order to close the pleural space and prevent air leaks. Although the underlying mechanism is controversial and there is no standardized administration amount and method, usually, numerous case reports, series, and retrospective or prospective studies have reported successful results (7). Pleurodesis compared with surgery has significantly increased the success rate, decreased the ICU stay and need for surgery, and reduced the overall hospital stay associated with decreased mortality $(8,9)$. Its success has encouraged us. We believe that it can be used for the treatment of chylothorax because it is easy to apply, painless, comfortable, fast, and cheap, without requiring analgesia or sedation during pleurodesis. We easily administered pleurodesis, and the chest tube was clamped for $2 \mathrm{~h}$ at the bedside without any complications (7-9). The first treatment option is surgery only for a small group of patients. Conservative treatments that should always be kept in mind are preferred by the majority of patients and successful in only half of the cases. Although the criteria for conservative treatment of thoracic duct injury has been described in the literature, the choice for the most appropriate treatment for patients is based on the clinician's experience and the patient's incomparable condition (6).

\section{Conclusion}

No similar case of postoperative chylothorax treated with pleurodesis using autologous blood has been found in the English literature. According to anatomical variations, the ductus thoracicus is susceptible to injury even in the hands of an experienced surgeon. In case an injury has occurred shortly after thoracic sympathectomy, autologous blood pleurodesis is an effective treatment for chylothorax. This procedure is safe and cheap and can be easily performed at the bedside.

Informed Consent: Written informed consent was obtained from patient who participated in this study.

Peer-review: Externally peer-reviewed. 
Author Contributions: Concept - M.C.., H.E., T.T.B., S.G.Ç.; Design - M.Ç., H.E., T.T.B., S.G.C..; Supervision - M.C.., H.E., T.T.B., S.G.C..; Resource - M.C,., H.E., T.T.B., S.G.C.; Materials - M.C.., H.E., T.T.B., S.G.C.; Data Collection and/ or Processing - M.C.., S.G.C.. ; Analysis and/or Interpretation - M.C.., S.G.C..; Literature Search - M.C.., S.G.C..; Writing - M.C.., S.G.C..; Critical Reviews - M.C.., S.G.C..

Conflict of Interest: The authors have no conflict of interest to declare.

Financial Disclosure: The authors declared that this study has received no financial support.

\section{References}

1. Macía I, Moya J, Ramos R, Rivas F, Urena A, Rosado G, et al. [Primary hyperhidrosis. Current status of surgical treatment]. Cir Esp 2010; 88: 146-51. [Article in Spanish] [CrossRef]

2. Sugimura H, Spratt EH, Compeau CG, Kattail D, Shargall Y. Thoracoscopic sympathetic clipping for hyperhidrosis: long-term results and reversibility. J Thorac Cardiovasc Surg 2009; 137: 1370-6. [CrossRef]

3. Reisfeld R, Nguyen R, Pnini A. Endoscopic thoracic sympathectomy for hyperhidrosis: experience with both cauterization and clamping methods. Surg Laparosc Endosc Percutan Tech 2002; 12: 255-67. [CrossRef]
4. Kumar S, Kumar A, Pawar DK. Thoracoscopic management of thoracic duct injury: Is there a place for conservatism? J Postgrad Med 200; 50: 57-9.

5. Apiliogullari B, Esme H, Yoldas B, Duran M, Duzgun N, Calik M. Early and midterm results of single-port video-assisted thoracoscopic sympathectomy. Thorac Cardiovasc Surg 2012; 60: 285-9. [CrossRef]

6. Stager V, Le L, Wood RE. Postoperative chylothorax successfully treated using conservative strategies Proc (Bayl Univ Med Cent) 2010; 23: 134-8 [CrossRef]

7. Muruganandan, S, Kumar S, Lee, YCG. Blood Patch for Pneumothorax: A Literature Review. Cur Pulmonol Rep, 2017; 6: 30-8. [CrossRef]

8. Alamdari DH, Asadi M, Rahim AN, Maddah G, Azizi S, Shahidsales S, et al. Efficacy and Safety of Pleurodesis Using Platelet-Rich Plasma and Fibrin Glue in Management of Postoperative Chylothorax After Esophagectomy. World J Surg 2018; 42: 1046-55. [CrossRef]

9. Akin H, Olcmen A, Isgorucu O, Denizkiran I, Dincer I. Approach to patients with chylothorax complicating pulmonary resection. Thorac Cardiovasc Surg 2012; 60: 135-9. [CrossRef]

Cite this article as: Çalık M, Esme H, Bekçi TT, Göknil Çalık S. Chylothorax: A Rare Complication of Endoscopic Thoracic Sympathectomy İstanbul Med J 2018; 19: 167-9. 